\title{
Relative impact of childhood and adulthood socioeconomic conditions on cause specific mortality in men
}

\author{
Øyvind Næss, Bjøgulf Claussen, George Davey Smith
}

J Epidemiol Community Health 2004;58:597-598. doi: 10.1136/jech.2003.012229

l ncreasing evidence suggests that social inequality in mortality risk in developed countries is mediated by social and biological chains of risk accumulating over the life course. ${ }^{1}$ Both childhood and adulthood socioeconomic conditions have been found to be independently associated with mortality risk. ${ }^{23}$ The relative importance of childhood and adulthood social conditions is likely to vary depending on cause of death. ${ }^{4}$ Lack of full life course cohorts with large enough study power prevents many researchers from studying this issue across causes of death.

\section{METHODS AND RESULTS}

A cohort of all inhabitants in Oslo aged 30-54 years in 1990 was linked to the Census, Tax, and the Death Registers, for 58751 people. Housing conditions from the 1960 census provided information on childhood social conditions. Six aspects of housing conditions were included in a housing index. This included information on rooms per household capita $(0,1,2)$, type of dwelling $(0,1,2)$, ownership $(0,1)$, toilet $(0,1)$, bath $(0,1)$, and telephone in dwelling $(0,1)$. This was summed for each individual and categorised to five approximately similar size groups. Income information for 1990, derived from taxation authorities, was used as the indicator of social conditions in adult age. Yearly wages, social security benefits, and other earnings were summed for the household, and divided by the number of consumers according to the following weights: 1.0 for the first adult person, 0.7 for spouse or child older than 16, and 0.5 under 16 years. The percentage of people across the five groups of housing conditions and income was fairly equal with $20 \%$ in the top and $20 \%$ in the bottom of the housing index, and $15 \%$ and $16 \%$ in the top and bottom income groups respectively. The age range for which 1960 census data provided evidence on childhood circumstances was determined by investigating age at marriage, because in Oslo at that time men would generally be registered as living in their parental home until marriage because of housing scarcity. The cut off point was chosen at the age where $97 \%$ were unmarried and this was evenly distributed across values of the housing index. Some did not answer all questions in the census, had zero income, or lived outside Norway in 1960 (34\%). Age adjusted mortality rates were 37.1 among the excluded and 46.1 among the included (per 10000 person years), suggesting small differences between the groups. To compare the relative influence of social conditions at two points in time a relative index of inequality was constructed.

Causes of death were the 10 most common causes of death during the years 1990-98. All death certificates are registered with Statistics Norway, without any missing cases. They were coded according to ICD-9 until 1996 and ICD-10 onwards (codes in ascending order): large bowel and rectum cancer (ICD-9: 153-154, ICD-10: C18-C21), lung cancer (ICD-9: 162, ICD-10: C34), malignant melanoma (ICD-9: 172, ICD-10: C43), psychiatric causes (ICD-9: 290, 292-302, 304, 306-319 and ICD-10: F00-F09, F11-F69), alcohol related diseases
(ICD-9: 291, 303, 305, 571 and ICD-10: F10, K70, Y91), other cardiovascular diseases (ICD-9: 390-409, 415-429, 440-459 and ICD-10: I00-I19, I26-I59, I70-I119), coronary heart disease (ICD-9: 410-414 and ICD-10: I20-I25), stroke (ICD-9: 430-438 and ICD-10: I60-I69), sudden unexpected deaths (ICD-9: 798-799 and ICD-10 R96, R98, R99), and violent deaths (ICD-9: 800-999 and ICD-10: S00-Y90, Y95-Y98).

Both the strength and the relative impact of childhood or adulthood social conditions varied by cause of death when the two points in time were unadjusted and mutually adjusted (table 1). Sudden unexpected deaths were more associated with childhood than adulthood conditions, the same was true for large bowel cancer, but with imprecise effect estimates. Coronary heart disease and stroke appeared similarly associated with childhood and adulthood social conditions. Lung cancer, psychiatric causes, alcohol related causes, and violent causes were more associated with adulthood social conditions. Malignant melanoma was inversely associated with social conditions but more so with adulthood then with childhood measures. The social gradient was particularly pronounced in psychiatric and alcohol related diseases for both points in time.

\section{COMMENTS}

The study adds support to the notion that particular causes are related to life course social conditions in a specific manner. Violent causes of death are, plausibly, determined by such conditions over a short period before death. Other causes are strongly related to health behaviour over adult life, such as alcohol related diseases and lung cancer, but such behaviours are set in train at a relatively young age. Yet other causes, such as coronary heart disease, appear strongly determined by childhood and adulthood factors.

The excess mortality in those with poor income in 1990 could represent reverse causality influencing various causes unevenly, such as with psychiatric causes. But with eight years of follow up this is not generally thought to be important. Because of fewer deaths from specific causes we did not analyse data for women in this report.

Various causes of death are thought to be differently related to social conditions across the life course because timing and duration of social and biological influences differ. These findings imply that future aetiological studies looking at specific causes should take into account how social determinants are experienced across the life course and

\section{Key points}

- The relative impact of childhood and adulthood social conditions varies by cause of death. This report presents further and more detailed evidence of this on the 10 most common causes of death. 
Table 1 Relative indices of inequality (RII) in 1960 and 1990 for cause specific mortality 1990-98 among male inhabitants in Oslo $199030-54$ years old ( $n=58751$ )

\begin{tabular}{|c|c|c|c|c|c|}
\hline Causes of death & $\begin{array}{l}\text { Number } \\
\text { of deaths }\end{array}$ & 1960 RII* (unadjusted) & $\begin{array}{l}1960 \text { RII* (mutually }^{*} \text { adjusted) }\end{array}$ & 1990 RII* (unadjusted) & $\begin{array}{l}1990 \text { RII* (mutually }^{*} \text { adjusted) }\end{array}$ \\
\hline $\begin{array}{l}\text { Cancer large bowel and } \\
\text { rectum }\end{array}$ & 68 & $2.10(0.91$ to 4.83$)$ & $2.10(0.91$ to 4.85$)$ & $0.95(0.40$ to 2.24$)$ & $0.91(0.38$ to 2.17$)$ \\
\hline Lung cancer & 104 & $2.48(1.26$ to 4.88$)$ & $2.36(1.20$ to 4.66$)$ & 3.88 (1.92 to 7.84$)$ & 3.77 (1.86 to 7.65$)$ \\
\hline Malignant melanoma & 49 & $0.53(0.19$ to 1.45$)$ & $0.57(0.21$ to 1.58$)$ & $0.22(0.07$ to 0.67$)$ & $0.23(0.08$ to 0.69$)$ \\
\hline Psychiatric & 122 & $13.09(5.91$ to 28.98$)$ & $10.60(4.79$ to 23.45$)$ & 28.55 (11.86 to 68.73$)$ & $24.94(10.31$ to 60.33$)$ \\
\hline Alcohol related diseases & 204 & $4.26(2.57$ to 7.05$)$ & $3.94(2.38$ to 6.51$)$ & $8.73(5.15$ to 14.81$)$ & $8.38(4.93$ to 14.26$)$ \\
\hline Coronary heart disease & 338 & $2.73(1.87$ to 4.00$)$ & $2.62(1.79$ to 3.83$)$ & $2.99(2.03$ to 4.41$)$ & $2.89(1.95$ to 4.27$)$ \\
\hline Stroke & 78 & $1.82(0.84$ to 3.95$)$ & $1.79(0.82$ to 3.88$)$ & $1.67(0.75$ to 3.72$)$ & $1.63(0.73$ to 3.64$)$ \\
\hline Other cardiovascular causes & 108 & $1.24(0.64$ to 2.39$)$ & $1.19(0.62$ to 2.31$)$ & 2.45 (1.23 to 4.87$)$ & $2.43(1.22$ to 4.84$)$ \\
\hline Sudden unexpected deaths & 92 & $3.23(1.55$ to 6.74$)$ & $3.15(1.51$ to 6.57$)$ & $1.92(0.92$ to 4.02$)$ & $1.83(0.87$ to 3.85$)$ \\
\hline Violent deaths & 376 & $1.77(1.23$ to 2.55$)$ & 1.65 (1.15 to 2.38$)$ & $4.22(2.87$ to 6.19$)$ & $4.12(2.80$ to 6.06$)$ \\
\hline All causes & 2147 & 2.25 (1.93 to 2.62$)$ & $2.15(1.85$ to 2.50$)$ & $2.83(2.42$ to 3.31$)$ & $2.74(2.34$ to 3.20$)$ \\
\hline
\end{tabular}

\section{Policy implications}

- The potential impact of measures in childhood and adulthood on health inequality at adult ages may vary by specific outcomes.

interventions against social inequalities in health will have to address this.

\section{ACKNOWLEDGEMENTS}

We thank Executive Officer Britt Elin Bråten and Project Leader Finn Gjertsen, Statistics Norway, for linking data, Professor Håkon K. Gjessing, University of Oslo, for statistical advice, and the European Science Foundation's programme "Social Variations in Health Expectancy in Europe" for support.

\section{Authors' affiliations}

$\varnothing$ Næss, B Claussen, Institute of General Practice and Community Medicine, University of Oslo, Norway

G Davey Smith, Department of Social Medicine, University of Bristol, UK

Funding: the work is financed by the governmental research fund Health and Rehabilitation in Norway and our university institutes.

Conflicts of interest: none declared.

Correspondence to: $\operatorname{Dr} \varnothing$ Næss, Institute of General Practice and Community Medicine, PO Box 1130 Blindern, N-0317 Oslo, Norway; oyvind.nass@samfunnsmed.vio.no

Accepted for publication 25 November 2003

\section{REFERENCES}

1 Ben-Shlomo Y, Kuh D. A life course approach to chronic disease epidemiology: conceptual models, empirical challenges and interdisciplinary perspectives. Int J Epidemiol 2002;31:285-93.

2 Ben-Shlomo Y, Davey Smith G. Deprivation in infancy or in adult life. Lancet 1991;337:1489-90.

3 Claussen B, Davey Smith G, Thelle D. Impact of childhood and adulthood socioeconomic position on cause specific mortality: the Oslo Mortality Study. J Epidemiol Community Health 2003;57:40-5.

4 Davey Smith G, Gunnel D, Ben-Shlomo Y. Life-course approaches to socioeconomic differentials in cause-specific adult mortality. In: Leon D, Walt $G$ eds. Poverty, inequality and health. Oxford: Oxford University Press, 2000:88-124.

5 Davey Smith G, Hart C, Hole D, et al. Education and occupational social class: which is the more important indicator of mortality risk? J Epidemiol Community Health 1998;52:153-60. 